\title{
Mother Positivity and Family Adjustment in Households with Children with a Serious Disability
}

\author{
Barry Trute $\cdot$ Karen M. Benzies • \\ Catherine Worthington
}

Published online: 21 April 2011

(C) The Author(s) 2011. This article is published with open access at Springerlink.com

\begin{abstract}
Only limited attention has been given to parent coping resources in the positive adjustment of families of children with a disability. This study is the first to explore maternal positivity as a psychological coping resource related to family adjustment in these families. Consistent with broaden-and-build theory and prior positivity research, positivity was operationalized through a ratio of positive to negative affect scores. We employed longitudinal tracking over a 1 year interval. Children's diagnostic categories included developmental conditions or impairments, mental health disorders, complex health conditions, physical/motor conditions or impairments, sensory impairments, and provisionally diagnosed conditions or impairments. We used a computer assisted telephone survey to gather psychological, family, and demographic information from 152 mothers in Alberta, Canada. Hierarchical regression analysis indicated mothers' level of positivity and age, when controlled for family adjustment at Time 1, accounted for $46 \%$ of the variance in family adjustment at Time 2 . That is, older mothers with higher positivity scores were found to live in households with
\end{abstract}

\section{B. Trute}

Faculty of Social Work, University of Manitoba, Winnipeg,

MB, Canada

B. Trute $(\square)$

Faculty of Social Work, University of Calgary,

2500 University Drive NW, Calgary, AB T2N 1N4, Canada

e-mail: btrute@ucalgary.ca

K. M. Benzies

Faculty of Nursing, University of Calgary, Calgary, AB, Canada

C. Worthington

School of Public Health and Social Policy, University

of Victoria, Victoria, BC, Canada higher levels of family adjustment after 1 year. These findings provide promising support for broaden-and-build theory, which posits that positive experienced emotions can offset and diminish the negative health and relationship impacts of chronic stress. Study findings support the salience of mothers' positivity as a psychological coping resource, which is related to enhanced family adjustment in situations of childhood disability.

Keywords Family adjustment $\cdot$ Child disability $\cdot$ Mother coping $\cdot$ Positivity $\cdot$ Longitudinal study

\section{Introduction}

There has been substantial interest in parental distress in the childhood disability literature (Helff and Glidden 1998), and relatively less attention has been given to positive parent and family consequences that can accrue in situations of childhood disability. Recently, researchers have studied the positive effects that a person with a disability can have on the life of a caretaker (Flaherty and Glidden 2000; Folkman 1997; Folkman and Moskowitz 2000; Green 2007; Hastings et al. 2002; Hastings et al. 2005; Hastings and Taunt 2002). It appears that many parents respond to the emotional and caregiving stressors that can be associated with childhood disability with positive coping and resiliency (Goodley and Tregaskis 2006; McKeever and Miller 2004). Coping and adjustment to loss, such as a parent's emotional response to their child's developmental challenges, has been found to be associated with finding benefit in the experience through a process of stress-related personal growth (Davis et al. 1998; Janoff-Bulman and Frantz 1997). Yet there remains only limited understanding of the processes that contribute 
to effective parent coping and family adjustment in general (Park 1998, 2010), and specifically in situations of childhood disability (Olsson and Hwang 2008).

In family situations of childhood disability, parent emotional response can best be summarized as times of sadness and times of joy (Trute et al. 2007). It seems that individuals may experience elements of both negative and positive emotions in response to the same life challenge, and these divergent emotions can co-occur, yet be mutually distinct (Larsen et al. 2001; Russell and Carroll 1999). Lazarus and Folkman (1984), in their pioneering research on the process model of stress and coping, assert that adaptive coping involves emotion management with the ability to reduce negative and enhance positive emotions. This early hypothesis has been tested, particularly in the health psychology literature (e.g., Stein et al. 1997). Positive experienced emotion has been shown to be important in adaptation to chronic stress situations as it is related to adaptive responses such as enhanced relational functioning (Folkman 1997). It is likely that higher levels of positive parental emotion valence is relevant to the understanding of resiliency in families of children with disabilities.

Building on the process model of stress and coping, positivity theory was introduced in the psychology literature by Fredrickson and her colleagues (Fredrickson 2001; Fredrickson 2009; Fredrickson and Losada 2005). They posit that negative and positive emotions co-exist, are variable over time rather than static, and serve different functions in stressful situations. While negative emotions limit attention to solve challenges, and deplete energy to deal with problems at hand, positive emotions broaden the scope of thinking and widen the boundaries of problem solving. Positivity thus builds personal and relational resources in parents as they respond to ongoing family challenges and seek their solution.

Through her broaden-and-build theory, Fredrickson (2001) posits that the experience of positive emotions, in response to a stressor or challenging event, serves to build enduring personal and social coping resources. She sees positive emotions as "not just end states in themselves but also a means to achieving psychological growth and improved well-being over time" (p. 218). Consistent with the broaden-and-build theory, Fredrickson et al. (2000) contend that positive emotions diminish the deleterious long-term influence and effects of negative emotions. That is, the experience of a higher ratio of positive emotion "puts the brakes on" negative emotions, and assists in an upward spiral towards strengthened resiliency to cope with stressors (Fredrickson 2009, p. 103). Positive affect, a "hallmark of well-being" (Lyubomirsky et al. 2005, p.803), can be an indicator of enhanced psychological coping resources. Positive emotions are seen as being endurable, and thus, a reserve of positive coping resources is built up over time that can be activated to respond to subsequent life challenges and situational stressors (Fredrickson and Losada 2005). It is "in-the-moment positive emotions, and not more general positive evaluations of one's life," that is the crucial element in the achievement of resilient coping (Cohn et al. 2009 p.361). This is not to suggest that positive emotions should dominate one's mental state, and that negative emotions are to be avoided or are inherently bad. It is recognized that appropriate negative affect serves to keep individuals "grounded, real, and honest" (Fredrickson 2009, p. 159).

Fredrickson and her colleagues operationally define positivity as a ratio of positive to negative affect (i.e., positivity $=$ positive affect/negative affect). When considering parent affective response to childhood disability, this can include a wide array of positive emotions, such as serenity, interest, hope, pride, amusement, inspiration, awe and love; and negative emotions such as frustration, sadness, fatigue, hopelessness, and anger. It is the parent's ability to maintain a "heart-felt" higher ratio of positive compared to negative emotions in the face of the stressor of having a child with a disability that will predict subjective well-being and social adjustment (Fredrickson 2009, p.16). Mother positivity may be important in the understanding of salient factors related to overall family adjustment in situations of childhood disability but has never been tested in this special child and family situation.

The research reported here is the first to explore the relationship of mother's positivity and family adjustment in households with a child with a disability. We tracked family adjustment over a 1 year interval in families of children with diagnosed developmental, mental health or health challenges. Our primary research objective was to test whether higher positivity in mothers of children with a disability can predict higher levels of mothers' assessment of family adjustment over a 1 year interval. This serves as an exploratory test of Fredrickson's broaden-and-build theory. It is also of research interest to explore whether socio-demographic characteristics of mothers, and of their children with a disability, are related to the relationship between mother positivity and long term family adjustment.

\section{Method}

\section{Participants}

A sampling frame was created with the assistance of Family Support for Children with Disabilities (FSCD), Alberta Children and Youth Services. FSCD is a government sponsored support program that is offered to all 
families of children with serious developmental disability or complex health challenges living in the Province of Alberta. Family support services are provided without fee and include a key or dedicated worker who coordinates community-based health and social services for children with a disability and their family members. The sampling frame $(N=1,019)$ included all families of children under 18 years of age, with first entry to disability services in the previous 3-12 months. See Fig. 1 for Flow of Participants. To preserve confidentiality, passive recruitment methods were used. An invitation to participate in the study was mailed to families by FSCD. A second invitation was sent to non-respondents 6 weeks later. This resulted in a response rate of $29 \%$, which is typical for this survey method. This response rate is a conservative estimate because the response rate calculation could not account for non-respondents who were ineligible (indeterminates) (Allison and Yoshida 1989).

At Time 1, the majority of participants $(82 \%, n=195)$ were mothers. Other participants were fathers $(6 \%)$, grandparents (4\%), step or adoptive parents (5\%), aunts/

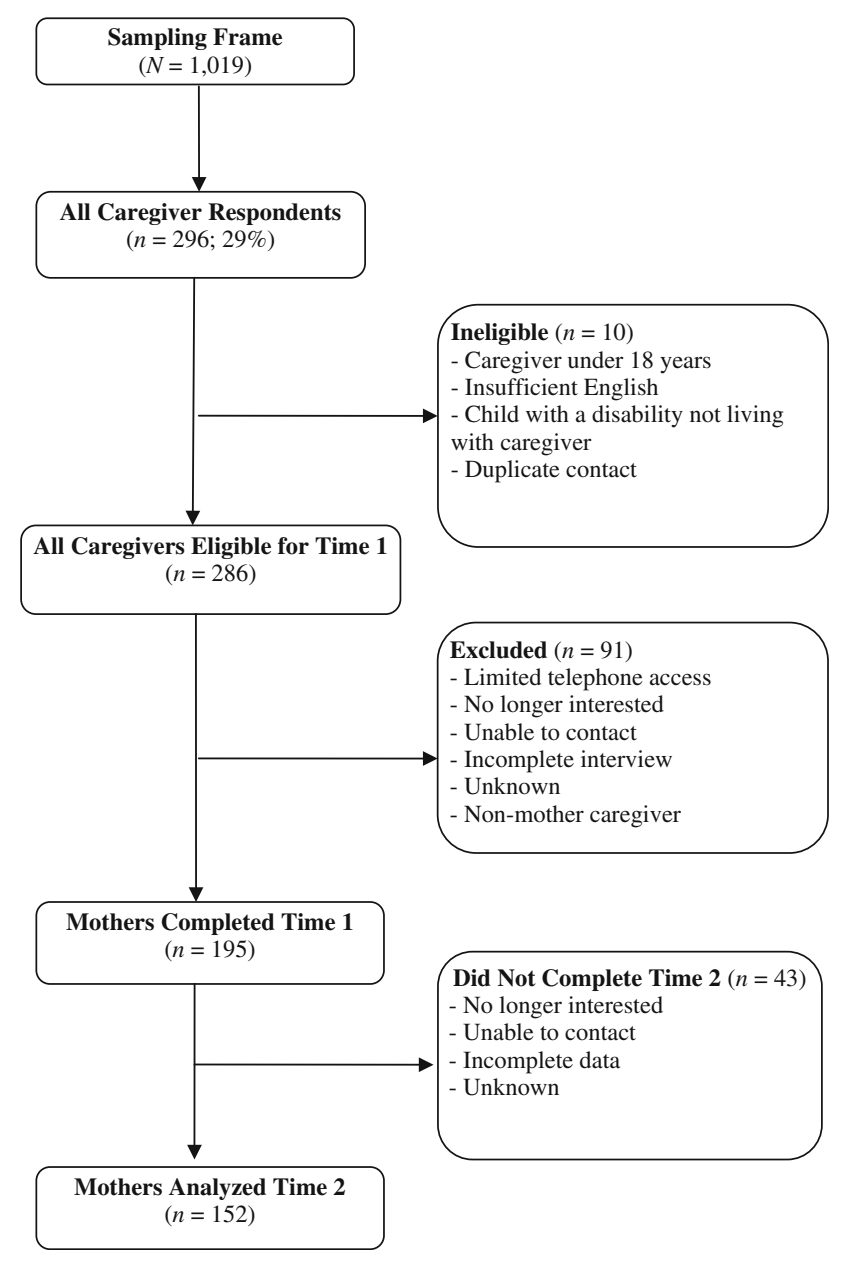

Fig. 1 Flow of participants uncles/cousins, or foster parents/guardians (3\%). For the purposes of the research reported in this paper, only mother survey information was used. There were three reasons for this. First, mothers constituted the largest proportion of the overall sample. Second, there are important gender differences in parental emotional response to childhood disability (Hastings et al. 2005; Trute 1995), in mothers' and fathers' coping with stress (Nagy and Ungerer 1990; Schilling et al. 1985), and in their differing assessment of their family needs (Bailey et al. 1992; Barnett et al. 1987). Third, there is evidence that when multiple measures of family environment are compared, confirmatory factor analysis suggests that mothers' assessment and independent observation measures converge (Kim Park et al. 2008).

\section{The Mothers}

At Time 2 the mothers were on average $37.9(\mathrm{SD}=6.3$; range $22-55$ years) years old, with the majority $(81.2 \%$, $n=125)$ married or cohabiting, and a small proportion were single parent mothers $(5.2 \%, n=8)$. The majority were employed $(64.3 \%, n=99)$. Of those employed, nearly a third $(48 \%, n=47)$ worked more than $30 \mathrm{~h}$ per week. Nearly one quarter $(23 \%, n=35)$ reported an annual household income less than $\$ 40,000$ (Canadian), which approximates the Canadian before-tax, low-income cut-off $(\$ 39,399)$ for a family of four in 2006 (Statistics Canada 2006).

\section{The Children}

The children with a disability ranged from 1 to 18 years (mean $=8.0$ years, $\mathrm{SD}=4.6$ ), had between zero and six siblings (sibling mode $=1,48 \%$ ) and $70 \%$ were male. The proportion of children with a prenatal diagnosis was 14\%; neonatal (under 28 days) 6\%. Age at diagnosis for the remaining children was as follows: infants (under 1 year) $6 \%$; toddlers (1-3 years) 25\%; preschool (4-5 years) $23 \%$; school-age (6-12 years) 23\%; and adolescent (13-18 years) $3 \%$. Diagnostic categories were: developmental conditions or impairments $(56 \%)$, mental health disorders $(18 \%)$, complex health conditions (12\%), physical/motor conditions or impairments $(7 \%)$, sensory impairments $(3 \%)$, and unconfirmed conditions or impairments $(4 \%)$.

Procedure

Respondents were screened for eligibility and were considered eligible to participate if they met the following criteria: (a) were a caregiver over the age of 18, (b) demonstrated a sufficient level of English language proficiency to complete a telephone interview, and (c) had a child with 
a disability living with them. There were no statistically significant differences between Time 1 and Time 2 on maternal age or child age, $F(1,192)=2.85, p=.2 .05$, or child sex, $\chi^{2}(1,195)=.588, p=.443$.

Computer Assisted Telephone Interviews (CATI) were conducted between May and September 2007 (Time 1) and again 1 year later (Time 2). CATI was employed to orally administer the surveys, including all scales, because it increases (a) data collection efficiency through automated dialing sequences and (b) data accuracy through direct data entry and upload to statistical software packages for analyses. CATI interviewers were trained to ensure sensitivity to the participants during the interviews, and were monitored for interview quality throughout the project. Two university-based review boards approved the research: one at the university where the study was conducted (University of Calgary), and one at the university with the research center that conducted the CATI (University of Alberta). Formal informed consent was obtained at the onset of each interview. Parents were mailed a gift certificate $(\$ 40$ Canadian) in recognition of their contribution to the study.

\section{Measures}

Brief Family Assessment Measure III (FAM-BF) General Scale. Family adjustment was assessed with the FAM-BF (Skinner et al. 1995), a brief 14-item version of the FAM. Mothers responded to items (e.g., "We never know what's going on in our family," and "We deal with our problems even when they're serious") on a 4-point Likert scale of 0 (strongly agree) to 3 (strongly disagree). Higher scores indicate lower family adjustment. Standardized T-scores below 40 indicate that the mother is reporting very effective family adjustment and scores above 60 indicate a disturbance in family adjustment. Test-rest reliability is $.56-.66$ over 12 days with high internal consistency (Cronbach $\alpha=.86-.94)$ (Skinner et al. 1995). For the present study, $\alpha=.88$.

Positive and Negative Affect Schedule (PANAS). Emotion was assessed with the 20-item PANAS (Watson et al. 1988). Time intervals used in prior research have ranged from right now to in the past year, without affecting the reliability $(\alpha=.86-.90$ for positive affect; $\alpha=.84-.87$ for negative affect). For the present study, mothers responded to how they felt in the past week (example PANAS items include positive feelings and emotions: "enthusiastic", "inspired", strong" and negative descriptors include: "distressed," "irritable", "upset"). Higher scores indicate greater positive or negative emotion. For the present study, $\alpha=.87$ and .89 for the positive and negative scales, respectively. We created a positivity ratio (PANASPR; positive affect score/negative affect score) for use in this study that is consistent with procedures followed in the positive psychology literature (Fredrickson and Losada 2005). The use of a positivity ratio, rather than separate positive and negative affect scores, was important in this study because the ratio represents the "affective texture of a person's life" (p. 678) and is hypothesized to predict subjective well-being (Fredrickson and Losada 2005).

\section{Data Analyses}

Prior to analyses, data were examined for linearity and normality. Q-Q plots, to compare probability distributions, confirmed linearity of dependent and independent variables. Pearson's correlations and multiple linear regressions were used for data analyses in SPSS version 16. Significance was set at $p<.05$ for all statistical tests.

Pearson's correlations were conducted with demographic variables collected at Time 1 to assess potential predictor variables of family adjustment (FAM-BF-2) at Time 2. These demographic variables included child age, child gender, mother age, mother education, family income, single parent family, family size, and number of children with a disability in each family. A dummy variable was created for the diagnostic category of developmental disability (i.e., the largest diagnostic group) compared to all other diagnostic categories combined.

Multiple linear regression was employed to test the amount of variance explained in family adjustment at Time 2 (FAM-BF-2). Variables selected for the regression were those found significant in the correlational analysis. Variables were entered in two blocks: Step 1, FAM-BF-1 and MOMAGE; Step 2, PANAS-PAR was added to assess the independent contribution of PANAS-PAR.

\section{Results}

\section{Standardized Scale Scores}

Positivity mean score $=1.8 \quad(\mathrm{SD}=.8)$. An empirical marker of level of positivity is the Losada line, which provides a potential cutting point in positivity ratio between people who flourish and those that languish under stress (Fredrickson and Losada 2005; Fredrickson 2009). Approximately $20 \%$ of the sample scored above the suggested Lasoda line or cutoff score for emotional flourishing under stress of 2.9. That is, approximately one mother in five was found to be flourishing in terms of their emotional coping resources.

On average, family adjustment scores were within the normal range of adjustment at both Time 1 and Time 2 . Approximately $30 \%$ of the families were in the excellent or strong range of family adjustment. Approximately 5\% of the families were in the problem or distressed range. 


\section{Pearson's Correlation}

None of the demographic variables were significantly related to family adjustment at Time 2 with the exception of mother age (MOMAGE) which showed a weak relationship ( $r=.17, p=.02)$ with older mothers having more positive family adjustment. Mothers' assessment of family adjustment at Time 1 was strongly related to their score of family adjustment at Time $2(r=.65, p<.001)$ (see Table 1). Positivity (PANAS-PR) was found to have a moderate relationship with family adjustment at Time 2 (FAM-BF-2) $(r=-.44, p<.001)$; indicating that higher positivity was related to better family adjustment.

\section{Multiple Linear Regression}

In Step 1, both MOMAGE and FAM-BF-1 significantly contributed to explain $44 \%$ of the variance in FAM-BF-2. In Step 2, all three predictor variables jointly explained $46 \%$ of the variance in family adjustment, with PANAS-PR adding $2 \%$ to the total variance explained $(F=5.19$ $(1,148), p<.02$, see Table 2$)$.

\section{Discussion}

We tested the broaden-and-build theory over a one year interval by assessing whether mothers' level of positivity at Time 1 was associated with family adjustment at Time 2 . We employed a statistical test in which level of family adjustment at Time 2 was predicted by positivity level at Time 1, when the relationship was controlled for family adjustment at Time 1 and mother age. Although our results were correlational, we were able to control for family adjustment at Time 1, thus providing stronger results than if we had been unable to control for influences at Time 1. A prospective study such as this one, in which maternal positivity precedes and predicts family adjustment at Time 2 , while controlling for baseline family adjustment, make

Table 1 Summary of Pearson's correlations, means, and standard deviations for predictor and outcome variables

\begin{tabular}{lllccc}
\hline Variable $^{\mathrm{a}}$ & 2 & 3 & 4 & $M$ & $\mathrm{SD}$ \\
\hline 1. FAM-BF-2 & $.65^{* *}$ & $-.44^{* * *}$ & $-.17^{*}$ & 10.68 & 5.92 \\
2. FAM-BF-1 & & $-.49^{* * * *}$ & .04 & 10.69 & 5.95 \\
3. PANAS-PR & & & .00 & 1.78 & 0.80 \\
4. Mother age (years) & & & & 37.9 & 6.35 \\
\hline
\end{tabular}

${ }^{a} N, 152$; FAM-BF-2, Family assessment measure-brief form at Time 2; FAM-BF-1, Family assessment measure-brief form at Time 1; PANAS-PR, Positive and negative affect schedule-positivity ratio

$* p<.05 ; * * p<.01 ; * * * p<.001$
Table 2 Hierarchical multiple regression analysis predicting family adjustment at time 2 from family adjustment at time 1, maternal age, and positivity ratio

\begin{tabular}{|c|c|c|}
\hline \multirow[t]{2}{*}{ Predictor } & \multicolumn{2}{|c|}{$\begin{array}{l}\text { Family adjustment at time } 1 \text {, maternal age, and } \\
\text { positivity ratio }\end{array}$} \\
\hline & $\Delta R^{2}$ & $\beta$ \\
\hline Step 1 & $.44 * * *$ & \\
\hline FAM-BF-1 & & $.64 * * *$ \\
\hline MOMAGE & & $.15^{*}$ \\
\hline Step 2 & $.02 * * *$ & \\
\hline FAM-BF-1 & & $.57 * * *$ \\
\hline MOMAGE & & $.15^{*}$ \\
\hline PANAS-PR & & $-.16^{*}$ \\
\hline Total adjusted $R^{2}$ & $.46 * * *$ & \\
\hline$n$ & 151 & \\
\hline
\end{tabular}

FAM-BF-2, Family assessment measure-brief form at Time 2; FAMBF-1, Family assessment measure-brief form at Time 1; PANAS-PR, Positive and negative affect schedule-positivity ratio; MOMAGE, mother's age

$* p<.05 ; * * p<.01 ; * * * p<.001$

plausible the assertion that maternal positivity influences family adjustment over time (Diener and Chan 2011).

However, controlling for family adjustment at Time 1, in the study of predictors of family adjustment at Time 2, does reduce the amount of variability in the dependent variable left to be explained by predictor variables. The dependent variable in this study, family adjustment, is a stable phenomenon over time intervals such as a one year period (Skinner et al. 1995), and in our sample, we found a strong correlation between family adjustment at Time 1 and Time $2(r=.65)$. Hence a large proportion of variance in family adjustment at Time $2\left(r^{2}=42 \%\right)$ was removed when controlled for family adjustment at Time 1 . In this circumstance, the amount of variance explained by maternal positivity is masked by the substantial amount of shared variance that has been removed from the regression equation prior to the entry of maternal positivity as a predictor variable. Therefore, percentage of variance explained by this predictor is less of a salient finding, than the finding that maternal positivity remained a significant predictor of family adjustment at Time 2 . The small proportion of variance explained by mothers' positivity $(2 \%)$ is not surprising given the relatively small amount of variance in family adjustment at Time 2 that remained to be explained, when variance in this dependent variable was controlled by family adjustment at Time 1 . As well, maternal positivity represents one of a complex array of factors that might predict family adjustment over time and its power as a sole predictor would not be expected to be substantial. These findings provide tentative support to broaden-and-build 
theory, in that mothers' positivity ratio, or proportion of positive to negative experienced emotions, is significantly related to higher levels of adjustment of their families over time in households with a child with a disability.

Our sample of families was, on average, in the normal range in scale score of family adjustment at both Time 1 and Time 2. This finding of family 'normality' also provided evidence replicating other family studies in which families with young children are best described as "normal families with special children", which are not generally characterized by high levels of family pathology (Ferguson 2002; Seligman and Darling 1997; Trute 1990). At this time there is limited understanding of the processes that contribute to effective parent coping and family adjustment in situations of childhood disability (Olsson and Hwang 2008; Park 1998). Our findings suggest that positivity may be a productive line of inquiry in the exploration of parent emotional coping and family adjustment of families with children with disability.

Mothers' age emerged as a significant predictor variable. Although mothers' age at Time 1 showed a weak relationship to family adjustment at Time 2 , this predictor variable was a significant joint predictor of family adjustment (with mother positivity) over the 1 year interval. These findings suggest that older mothers, with higher positivity at Time 1, do show higher levels of family adjustment in the longer term. One might speculate that the older mothers have maintained positivity over longer time periods, and this has served to 'broaden and build' their personal resilience and ability to cope with family stressors. This finding does offer modest support to the assertion of Fredrickson and her colleagues that higher levels of positivity have a cumulative effect over time, and thereby build a reservoir of psychological resources to assist coping with chronic stressors (Fredrickson 2009).

Fredrickson and Losada (2005) predict that the Losada line or "a ratio of positive to negative affect at or above 2.9 will characterize individuals in flourishing mental health" (p.678) with an increased capacity for coping in stressful situations. We speculate that the 2.9 cutoff score may not be appropriate for mothers of children with disability. Given that research has indicated families with children with a disability are under significantly higher stress than other families (e.g., Hauser-Cram et al. 2001; Olsson and Hwang 2008), and given that at times transient negative affect or experienced emotions can be a realistic parent response to special child care and sometimes challenging family circumstances (e.g., fatigue, worry, etc.), we would anticipate that an adjusted Losada line would be appropriate for this special family context. We noted that on the measure of family adjustment, approximately $30 \%$ of our sample of families scored in the excellent or strong score range, and $20 \%$ were above the Losada cut-off score of 2.9 for psychological resiliency. Mothers in this sub-set of our study families, that scored in the strong range of standardized scores of family functioning, averaged a positivity score of 2.1. The determination of a Losada line for mental health and psychological well-being of parents of children with a disability requires further research attention.

The sample for this telephone survey included only mothers. Caution is required when generalizing the findings of this study to both mothers and fathers because of salient gender differences in parental psychological adjustment to childhood disability (Trute 1995). Given that the sample was comprised largely of Canadians of European descent with little representation of minority populations, caution should be exercised in assuming findings can be generalized to other demographic subgroups. There may also have been selection bias in favour of well-functioning families, as we did not have information on nonresponding families. In addition, because Canada has a universal health-care plan and the Province of Alberta a legislated family support program for families with children with serious disability, our findings in regard to maternal coping and family adjustment in situations of childhood disability need to be appreciated in this Canadian context.

The statistical analyses employed in this study were appropriate to the research question and size of sample. Care needs to be exercised in assuming causal linkages between predictor and target variables as this would require a larger sample to support analyses such as path analysis to test the direction and strength of the inter-related variables.

The findings of this survey should be viewed as preliminary because of the overall response rate, which was expected given the sampling limitations of telephone surveys, but promising enough to call for continued research. Our study findings do urge expanded research attention be given to parents' positivity, and to how positivity may be better understood to be associated with family adjustment across major types of childhood disability.

Acknowledgments This research was supported by operating grants from the Alberta Centre for Child, Family and Community Research (06040TD and 08-SM-Benzies)

Open Access This article is distributed under the terms of the Creative Commons Attribution Noncommercial License which permits any noncommercial use, distribution, and reproduction in any medium, provided the original author(s) and source are credited.

\section{References}

Allison, K. R., \& Yoshida, K. K. (1989). Increasing response rates in community health surveys administered by telephone. Canadian Journal of Public Health, 80, 67-70. 
Bailey, D., Blasco, P., \& Simeonsson, R. J. (1992). Needs expressed by mothers and fathers of young children with disabilities. American Journal on Mental Retardation, 97(1), 1-10.

Barnett, R. C., Biener, L., \& Baruch, G. (1987). Gender and stress. University of Michigan, MI: Free Press.

Cohn, M. A., Fredrickson, B. L., Brown, S., Mikels, J. A., \& Conway, A. M. (2009). Happiness unpacked: Positive emotions increase life satisfaction by building resilience. Emotion, 9, 361-368.

Davis, C. G., Nolen-Hoeksema, S., \& Larson, J. (1998). Making sense of loss and benefiting from the experience. Journal of Personality and Social Psychology, 75, 261-574.

Diener, E., \& Chan, M. Y. (2011). Healthy people live longer: Subjective well-being contributes to health and longevity. Applied Psychology: Health and Well-Being, 3, 1-43.

Ferguson, P. M. (2002). A place in the family: A historical interpretation of research on parental reactions to having a child with a disability. The Journal of Special Education, 36(3), 124-130.

Flaherty, E., \& Glidden, L. M. (2000). Positive adjustment in parents rearing children with Down Syndrome. Early Education and Development, 11(4), 407-422.

Folkman, S. (1997). Positive psychological states and coping with severe stress. Social Science and Medicine, 45(8), 1207-1221.

Folkman, S., \& Moskowitz, J. T. (2000). Positive affect and the other side of coping. American Psychologist, 55(6), 647-654.

Fredrickson, B. L. (2001). The role of positive emotions in positive psychology: The broaden-and-build theory of positive emotions. American Psychologist, 56, 218-226.

Fredrickson, B. L. (2009). Positivity. New York, NY: Crown Publications.

Fredrickson, B. L., \& Losada, M. F. (2005). Positive affect and the complex dynamics of human flourishing. American Psychologist, 60, 678-686.

Fredrickson, B. L., Mancuso, R. A., Branigan, C., \& Tugrade, M. M. (2000). The undoing effect of positive emotions. Motivation and Emotion, 24, 237-258.

Goodley, D., \& Tregaskis, C. (2006). Storying disability and impairment: Retrospective accounts of disabled family life. Qualitative Health Research, 16(5), 630-646.

Green, S. E. (2007). "We're tired, not sad": Benefits and burdens of mothering a child with a disability. Social Science and Medicine, 64, 150-163.

Hastings, R. P., \& Taunt, H. M. (2002). Positive perceptions in families of children with developmental disabilities. American Journal on Mental Retardation, 107(2), 116-127.

Hastings, R. P., Allen, R., McDermott, K., \& Still, D. (2002). Factors related to positive perceptions in mothers of children with intellectual disabilities. Journal of Applied Research in Intellectual Disabilities, 15, 269-275.

Hastings, R. P., Beck, A., \& Hill, C. (2005). Positive contributions made by children with an intellectual disability in the family: Mothers' and fathers' perceptions. Journal of Intellectual Disabilities, 9(2), 155-165.

Hauser-Cram, P., Warfield, M. E., Shonkoff, J. P., Krauss, M. W., Sayer, A., \& Upshur, C. C. (2001). Children with disabilities: A longitudinal study of child development and parent well-being. Monographs of the Society for Research in Child Development, 66 (3, Serial No. 266).

Helff, C. M., \& Glidden, L. M. (1998). More positive or less negative? Trends in research on adjustment of families rearing children with developmental disabilities. Mental Retardation, 36(6), 457-464.

Janoff-Bulman, R., \& Frantz, C. M. (1997). The impact of trauma on meaning: From meaningless world to meaningful life. In M.
Power \& C. R. Brewin (Eds.), The transformation of meaning in psychological therapies (pp. 91-106). New York, NY: Wiley.

Kim Park, I. J., Garber, J., Ciesla, J. A., \& Ellis, B. (2008). Convergence among multiple methods of measuring positivity and negativity in family environment: Relation to depression in mothers and their children. Journal of Family Psychology, 22, $123-134$.

Larsen, J. T., McGraw, A. P., \& Cacioppo, J. T. (2001). Can people feel happy and sad at the same time? Journal of Personality and Social Psychology, 81, 684-696.

Lazarus, R., \& Folkman, S. (1984). Stress. appraisal and coping. New York, NY: Springer.

Lyubomirsky, S., King, L., \& Diener, E. (2005). The benefits of frequent positive affect: Does happiness lead to success? Psychological Bulletin, 6, 803-855.

McKeever, P., \& Miller, K. (2004). Mothering children who have disabilities: A Bourdieusian interpretation of maternal practices. Social Science and Medicine, 59(6), 1177-1191.

Nagy, S., \& Ungerer, J. A. (1990). The adaptation of mothers and fathers to children with cystic fibrosis: A comparison. Children's Health Care, 19, 147-154.

Olsson, M. B., \& Hwang, C. P. (2008). Socioeconomic and psychological variables as risk and protective factors for parental well-being in families of children with intellectual disabilities. Journal of Intellectual Disability Research, 52, 1102-1113.

Park, C. L. (1998). Stress-related growth and thriving through coping: The roles of personality and cognitive processes. Journal of Social Issues, 54, 267-277.

Park, C. L. (2010). Making sense of the meaning literature: An integrative review of meaning making and its effects on adjustment to stressful life events. Psychological Bulletin, 136, 257-301.

Russell, J. A., \& Carroll, J. M. (1999). On the bipolarity of positive and negative affect. Psychological Bulletin, 125, 3-30.

Schilling, R. F., Schinke, S. P., \& Kirkham, M. A. (1985). Coping with a handicapped child: Differences between mothers and fathers. Social Science and Medicine, 21, 857-863.

Seligman, M., \& Darling, R. B. (1997). Ordinary families, special children: A systems approach to childhood disability (2nd ed.). New York, NY: Guildford.

Skinner, H. A., Steinhauer, P., \& Santa-Barbara, J. (1995). FAM-III Manual. Toronto, ON: Multi-health Systems.

Statistics Canada. (2006). Income of Canadians. Retrieved July 20, 2010, from www.statcan.ca/Daily/English/060330/d060330a.htm.

Stein, N. L., Folkman, S., Trabasso, T., \& Richards, T. A. (1997). Appraisal and goal processes as predictors of psychological wellbeing in bereaved caregivers. Journal of Personality and Social Psychology, 72, 872-884.

Trute, B. (1990). Child and parent predictors of family adjustment in households containing young developmentally disabled children. Family Relations, 39, 292-297.

Trute, B. (1995). Gender differences in the psychological adjustment of parents of young, developmentally disabled children. Journal of Child Psychology and Psychiatry, 36, 1225-1242.

Trute, B., Hiebert-Murphy, D., \& Levine, K. (2007). Parental appraisal of the family impact of childhood developmental disability: Times of sadness and times of joy. Journal of Intellectual and Developmental Disability, 32(1), 1-9.

Watson, D., Clark, L. A., \& Tellegen, A. (1988). Development and validation of brief measures of positive and negative affect: The PANAS scales. Journal of Personality and Social Psychology, 54(6), 1063-1070. 